\title{
ATOS DE CURRÍCULO E RE-EXISTÊNCIA NA CIBERCULTURA
}

\section{CURRICULUM ACTS AND RE-EXISTENCE IN CYBERCULTURE}

\section{ACTOS CURRICULARES Y RE-EXISTENCIA EN CIBERULTURA}

\author{
Vivian Martins ${ }^{1}$ \\ Joelma Fabiane Ferreira de Almeida ${ }^{2}$ \\ Wallace de Almeida Carriço ${ }^{3}$
}

\section{RESUMO}

O presente dossiê apresenta como temática principal os atos de currículo e re-existência na cibercultura, com artigos que transversalizam diferentes espaçostempos da educação, com práticas em diversas modalidades e regiões do Brasil. Contando com artigos de temáticas variadas dentro das tecnologias digitais em rede, apostamos na pluralidade de possibilidades que a educação contemporânea nos mostra, construindo uma rede de saberes inspiradores. No momento da publicação desse dossiê, de distanciamento social físico imposto pela Covid-19, as práticas expostas nesses artigos são mais do que bem-vindas, são necessárias e contribuem para um fazerpensar docente em situação de excepcionalidade. Os textos que compõem este dossiê abordam temas como táticas pedagógicas dos professores nômades no ciberespaço, o perfil do professor na cibercultura, e-learning como ferramenta digital híbrida, ativismo de mulheres nas redes sociais, o aplicativo Whatsapp no ensino de biologia, memes e 'conversas' com professoras em tempos de pandemia e cultura maker e pensamento computacional no ensino fundamental. Pesquisas com diferentes metodologias, epistemologias e abordagens teóricas, que apresentam achados que podem contribuir sobremaneira para práticas educacionais com usos de artefatos tecnológicos, em especial em um

\footnotetext{
${ }^{1}$ Professora do Instituto Federal do Rio de Janeiro (IFRJ). Doutoranda pelo Programa de Pós-graduação em Educação ProPEd/UERJ. Membro do Grupo de Pesquisa Docência e Cibercultura (GPDOC). Currículo Lattes: http://lattes.cnpq.br/2839844705473657. Email: vivian.martinst@gmail.com

2 Professora do Instituto Federal do Pará (IFPA). Doutoranda pelo Programa de Pós-graduação em Educação ProPEd/UERJ. Membro do Grupo de Pesquisa Docência e Cibercultura (GPDOC). Currículo Lattes: http://lattes.cnpq.br/2031704433559510. Email: elma.faby.ane@ gmail.com

${ }^{3}$ Professor de Ensino Fundamental da Secretaria Municipal de Educação do Rio de Janeiro (SME-RJ) e Mediador da disciplina Informática na Educação, do curso de Pedagogia a distância da UERJ. Doutorando pelo Programa de Pós-Graduação em Educação, Contextos Contemporâneos e Demandas Populares - PPGEduc UFRRJ. Membro do Grupo de Pesquisa Docência e Cibercultura (GPDOC). Currículo Lattes: http://lattes.cnpq.br/6246998456973189. Email: wallace.almeida@me.com
}

\begin{tabular}{|l|l|l|l|l|l|l|} 
(C) Redoc & Rio de Janeiro & v. 4 & n. 2 & p. 13 & Mai/Ago 2020 & ISSN 2594-9004
\end{tabular}


momento de ressignificação da profissão docente como o que estamos vivendo. Atuamos na esperança que esses textos inspirem pessoas e sejam levados a múltiplos espaços educacionais, para uma educação socialmente referenciada, problematizadora, de qualidade e que garanta o direito de acesso, permanência e êxito.

Palavras-chave: educação, cibercultura, atos de currículo, re-existência nas redes digitais.

\begin{abstract}
This dossier presents as main theme the acts of curriculum and re-existence in cyberculture. The articles cross different spaces of education, with practices in different modalities and regions of Brazil. Counting on articles with varied themes within digital network technologies, we bet on the plurality of possibilities that contemporary education shows us. The articles are building a network of inspiring knowledge. At the time of publication of this dossier, we are living in physical social distance imposed by Covid-19. The practices exposed in these articles are more than welcome, they are necessary and contribute to teach in an exceptional situation. The texts that compose this dossier address topics such as pedagogical tactics of nomadic teachers in cyberspace, the profile of the teacher in cyberculture, e-learning as a hybrid digital tool, women's activism in social networks, the Whatsapp application in teaching biology, memes and 'conversations' with teachers in times of pandemic and culture maker and computational thinking in elementary school. Research with different methodologies, epistemologies and theoretical approaches, which present findings that can greatly contribute to educational practices with the use of technological artifacts, especially in a moment of resignification of the teaching profession. We act in the hope that these texts will inspire people and it will send to multiple educational spaces, for a socially referenced, problematizing, quality education that guarantees the right of access, permanence and success.
\end{abstract}

Keywords: education, cyberculture, curriculum acts, re-existence on digital networks.

\title{
RESUMEN
}

Este dossier presenta como tema principal los actos curriculares y la reexistencia en la cibercultura, con artículos que cruzan diferentes espacios de educación, con prácticas en diferentes modalidades y regiones de Brasil. Contando con artículos con temas variados dentro de las tecnologías de redes digitales, apostamos por la pluralidad de posibilidades que la educación contemporánea nos muestra, construyendo una red de conocimiento inspirador. En el momento de la publicación de este dossier, del desapego social físico impuesto por Covid-19, las prácticas expuestas en estos artículos son más que bienvenidas, son necesarias y contribuyen a que los docentes se encuentren en una situación excepcional. Los textos que componen este dossier abordan temas como las tácticas pedagógicas de los docentes nómadas en el ciberespacio, el perfil del docente en cibercultura, el aprendizaje electrónico como una herramienta digital híbrida, el activismo de las mujeres en las redes sociales, la aplicación de Whatsapp en la enseñanza de biología y creador de culturas, memes y "conversaciones" con profesores en tiempos de pandemia y pensamiento computacional en la escuela primaria. Investigación con diferentes metodologías, epistemologías y enfoques teóricos, que presentan hallazgos que pueden contribuir en gran medida a las prácticas educativas con el uso de artefactos tecnológicos, especialmente en un momento de resignificación de la profesión docente 
como la que estamos experimentando. Actuamos con la esperanza de que estos textos inspiren a las personas y sean llevados a múltiples espacios educativos, para una educación socialmente referenciada, problemática y de calidad que garantice el derecho de acceso, permanencia y éxito.

Palabras clave: educación, cibercultura, actos curriculares, reexistencia en redes digitales.

\title{
EDUCAÇÃO NA CIBERCULTURA: ATOS DE CURRÍCULO E RE- EXISTÊNCIA EM REDE
}

\begin{abstract}
Se queremos compreender os processos pelos quais as pessoas constroem cotidianamente currículos, seus sentidos e significados, sejam essas pessoas técnicos, professores, gestores, coordenadores, estudantes, pais, líderes comunitários, entre outros atores sociais e institucionais, temos que ir, compreensivamente, ao encontro dos atos de currículo, suas realizações, seus
\end{abstract} motivos, suas crenças, seus pontos de vista e justificativas.

(MACEDO, 2013, p. 430)

A "Re-DoC", uma publicação do Grupo de Pesquisas Docência e Cibercultura - GPDOC da UERJ, do Programa de Pós-graduação em Educação, coordenado pela professora Edméa Santos, objetiva, neste dossiê, promover e fomentar a discussão sobre a temática "Atos de Currículo e Reexistência na Cibercultura", e suas implicações em diferentes contextos educacionais.

A opção por esse tema parte da concepção sobre currículo em ato como uma perspectiva relacional entre instituído e instituinte, teorias, pensamentos e práticas, forma e conteúdo, tudo junto, misturado e enredado. Para além dos escritos de um currículo formal, abordamos ações humanas, sociais, politicas e historicamente situadas, as quais apresentamos neste dossiê em toda sua complexidade, contradição e ambivalência, porque as consideramos fundantes da formação.

Isso implica refletir, a partir de experiências vividas, as descobertas e os desafios impostos à aprendizagem e à formação humana e, portanto, ao currículo em si. Vislumbramos os saberesfazeres educativos como possibilidades diversas de reinventar as formas de se estar no mundo e ampliar as compreensões de um novo desenho cultural, social, político e estético, que deixa suas marcas, afetando-as e sendo afetado pelas diversas redes educativas.

A formação é considerada por Macedo (2014) como o fenômeno fundante da educação. É por ela e para ela que atos de currículo são elaborados, guiados por saberes problematizados, contextualizados e críticos para práticas antropossociais. Não cabe uma explicação à formação, poderíamos 




\section{Revista Docência e Cibercultura}

explicar as condições e os dispositivos acionados para que ela pudesse acontecer, já que é um processo individual e do âmbito experiencial, ou seja, acontece a partir das experiências dos envolvidos.

Assim, nos artigos que compõem esta publicação, compartilhamos reflexões sobre a educação praticadapensada dentrofora da escola e da universidade, por professores e estudantes como formas de resistência na luta pela educação pública, laica, de qualidade e para todos. Diversas ideias e realidades são apresentadas em textos autorais e criativos, capazes de despertar ideias e pensamentos, opiniões e sensações, potencializando os diálogos sobre a importância de se conceber o ato educativo como um fazerpensar que demanda articulação e vivência de diferentes saberes, científicos ou não.

Para pensar a educação na cibercultura: atos de currículo e re-existência em rede, a presente edição da Revista Docência e Cibercultura (Re-DoC), v.4, n.2, traz múltiplas problematizações e análises. A seção Número Temático aborda a "ATOS DE CURRÍCULO E RE-EXISTÊNCIA NA CIBERCULTURA". Essa seção contém artigos que refletem a respeito da educação contemporânea em diversos contextos, espaços e redes, mediada pelas tecnologias digitais. Os artigos desse dossiê apresentam diferentes abordagens teóricas e metodológicas e estão listados a seguir:

O primeiro artigo "Professores nômades: re(construindo) táticas pedagógicas no ciberespaço" de Emerson dos Santos Lima e Rozevania Valadares de Meneses César anuncia uma reflexão a respeito dos nômades digitais, apresentando o conceito de professores nômades. Os autores optaram pela netnografia de Fragoso, Recuero e Amaral (2016) como metodologia e a categoria de análise tática de Certeau (1998), buscando compreender os modos de trabalho utilizados pelos nômades digitais. Como resultado, os autores verificaram que as práticas dos professores nômades caminham na mesma perspectiva dos professores que atuam na sala de aula convencional, com a diferença que os professores nômades utilizam as oportunidades das interfaces tecnológicas para vender cursos e desenvolver trabalhos criativos e colaborativos, fazendo a convergência entre as mídias e não transmidiação dos conteúdos.

O segundo artigo intitulado "O perfil necessário ao professor frente à influência da cibercultura no contexto educacional" de Rejuany Nora Klein da Silva, está voltado para os estudos da cibercultura e como ela ressignificou nossas relações em todas as esferas da sociedade. A autora direciona olhar especial para a educação e como nossa cultura faz emergir novas relações com o 


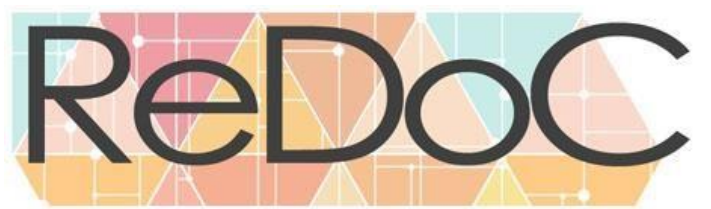

\section{Revista Docência e Cibercultura}

saber, exigindo uma postura diferenciada dos profissionais da educação. O artigo é iniciado apresentando um histórico da cibercultura, com a sua definição e como cada meio de comunicação traz consigo um ciclo cultural próprio. Na sequência, a autora apresenta as conexões com a educação, de forma a nos situar contextualmente sobre o momento em que estamos vivendo nessa área do conhecimento. Então, são evidenciados pontos que conduzem à formação docente como essencial para um novo perfil de professor, frente à influência da cibercultura no contexto educacional.

O terceiro artigo é intitulado "E-learning como ferramenta digital híbrida: uma metodologia colaborativa na formação técnica”, de autoria de Ricael Spirandeli Rocha, Gustavo Prado Oliveira e Gyzely Suely Lima. O relato de experiência versa sobre o e-learning, conceituado pelos autores como aprendizado eletrônico que contribui no incentivo e disposição do acesso à informação no processo de ensino e aprendizagem. O objetivo do artigo é evidenciar a utilização do e-learning como ferramenta digital híbrida em um contexto pedagógico e colaborativo na formação técnica. Os autores optaram por realizar um relato de experiência de caráter descritivo e exploratório com uma abordagem quanti-qualitativa. Os resultados da pesquisa apontaram para a aprendizagem híbrida e colaborativa, desempenho significativo, liberdade e autonomia dos estudantes a partir da utilização do e-learning, contribuindo na construção do conhecimento em conjunto.

"Todo espaço é político: ativismo de mulheres nas redes sociais" é o quarto artigo do dossiê e as autoras são Desirée Pires e Amanda Motta Castro. O artigo é proveniente de uma pesquisa de mestrado desenvolvida no Programa de Pós-graduação em Educação/PPGEDU da Universidade Federal do Rio Grande/FURG. A opção metodológica das autoras foi o levantamento bibliográfico e a temática versa sobre o ciberfeminismo: o ativismo de mulheres nas redes sociais. A pergunta central do artigo é: o que foi produzido no Brasil sobre o ativismo de mulheres nas redes sociais na última década? As autoras contextualizam a maior articulação dos movimentos sociais e, em especial, o movimento feminista, ao longo da última década, com forte utilização das redes sociais para propagação de suas pautas. Como exemplo em contexto brasileiro, temos as manifestações como a Marcha das Vadias (2015) e o \#EleNão (2018), demonstrando que o movimento feminista também vai para as ruas, não permanecendo somente nas redes sociais. Com um recorte para a última década, o levantamento bibliográfico das autoras apresenta as produções científicas brasileiras sobre o ativismo de mulheres com articulação e organização através das redes sociais. 


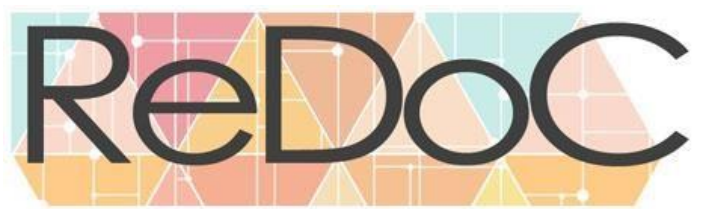

\section{Revista Docência e Cibercultura}

O quinto artigo de autoria de Douglas Carvalho Amorim é intitulado "Potencial pedagógico do aplicativo whatsapp no ensino de Biologia: percepções dos professores”. O contexto do artigo é marcado pelo advento de dispositivos móveis que proporcionaram uma mudança significativa nas formas de comunicação contemporâneas. O objetivo do estudo foi analisar o potencial pedagógico do Whatsapp no ensino de Biologia. Pensando em uma proposta de ensino mais dialógica, com maior respeito à realidade dos estudantes e que proporcione a integração entre espaços formais e informais, visando uma aprendizagem contínua. $\mathrm{O}$ autor realizou entrevistas semiestruturadas com dois professores de Biologia e a análise de conteúdo foi a técnica selecionada para a conversa com os dados emergentes. A pesquisa revelou que, com adequada mediação pedagógica dos professores, o aplicativo Whatsapp possui um potencial pedagógico no ensino de diferentes conteúdos de Biologia.

O sexto artigo chama-se "Memes, tecnologias e educação: 'conversas' com professoras em tempos de pandemia" e é de autoria de Elaine Sotero e Brenda Coutinho. O artigo apresenta um recorte para o uso das tencnologias em contexto de pandemia de COVID-19, onde encontros presenciais estão restringidos e escolas fechadas. As autoras refletem a respeito da utilidade do uso dos artefatos tecnológicos nesse momento para criação conteúdos didáticos, aulas e debates online. A valorização da instituição educacional no presente contexto contraria a posição substituível da escola, proporcionando pensamentos sobre transformações curriculares. A provocação das autoras é realizada no sentido de entender como serão o mundo e as escolas após a pandemia.

Cultura maker na educação através do Scratch visando o desenvolvimento do pensamento computacional dos estudantes do $5^{\circ}$ ano de uma escola do campo da cidade de Olinda-PE é o sétimo artigo e conta com a autoria de Sebastiao da Silva Vieira e Marcelo Sabbatini. Visando a participação dos estudantes de forma crítica, lúdica e colaborativa, o trabalho versa sobre a criação de uma cultura maker e o pensamento computacional no espaço escolar. O objetivo da pesquisa é analisar como o Scratch potencializa o desenvolvimento do pensamento computacional nos estudantes do Ensino Fundamental anos iniciais de uma Escola Rural da cidade de Olinda-PE. A metodologia utilizada pelos autores possui caráter qualitativo, com o desenvolvimento de entrevistas semiestruturadas e observação participante. Os autores relatam o uso do software Scratch visando o desenvolvimento do pensamento computacional com um grupo de alunos do $5^{\circ}$

ano do Ensino Fundamental. Os resultados encontrados pelos autores perpassam pelas 


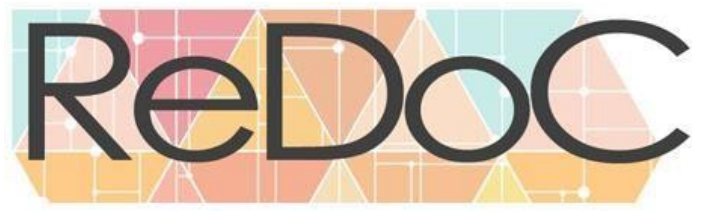

\section{Revista Docência e Cibercultura}

potencialidades do Scratch como um importante aliado na aprendizagem criativa, com participação ativa e motivação. A curiosidade dos estudantes em aprender a criação de jogos digitais, a lógica e programação e o desenvolvimento do pensamento computacional foi um ponto importante. Os autores pontuam que "os estudantes mostraram interesse, curiosidade e espontaneidade ao resolver os problemas propostos", o que consideramos ser fundamental para uma aprendizagem significativa.

Diante de tantos artigos interessantes, acreditamos que o dossiê cumpriu com seu objetivo de relatar atos de currículo e re-existência na cibercultura. As autorias plurais são repletas de subjetividades e contam histórias de vida, pesquisa e formação, com complexas políticas de sentido. De modo a intervir no mundo, as autorias materializadas em forma de artigos científicos constroem pontes para diferentes lugares que o leitor desejar ir, apresentando diversos contextos educacionais de diferentes regiões do país. $\mathrm{O}$ dossiê apresenta propostas plurais de educação, vamos nos inspirar em práticas interessantes e implicadas com a qualidade dos processos educativos. Dessa forma, desejamos aos leitores uma boa imersão nessas histórias da educação contemporânea.

\section{REFERÊNCIAS}

ALMEIDA, Wallace Carriço de. ATOS DE CURRÍCULO NA PERSPECTIVA DE APPLEARNING. Revista Docência e Cibercultura, v. 4, n. 2, maio-ago, 2020, p. 225-234. DOI: https://doi.org/10.12957/redoc.2020.52475

AIRES, Letícia. RESENHA CRÍTICA DO LIVRO “A PÓS-VERDADE É VERDADEIRA OU FALSA?", DE LÚCIA SANTAELLA. Revista Docência e Cibercultura, v. 4, n. 2, maiago, 2020, p. 242-249. DOI: https://doi.org/10.12957/redoc.2020.51190

AMORIM, Douglas Carvalho. POTENCIAL PEDAGÓGICO DO APLICATIVO WHATSAPP NO ENSINO DE BIOLOGIA: PERCEPÇÕES DOS PROFESSORES. Revista Docência e Cibercultura, v. 4, n. 2, maio-ago, 2020, p. 21-42. DOI:

https://doi.org/10.12957/redoc.2020.49789

LIMA, Emerson dos Santos; e CÉSAR, Rozevania Valadares de Meneses. PROFESSORES NÔMADES: RE(CONSTRUINDO) TÁTICAS PEDAGÓGICAS NO CIBERESPAÇO. Revista Docência e Cibercultura, v.4, n.2, maio-ago, 2020, p. 119-142. DOI: https://doi.org/10.12957/redoc.2020.51388

MACEDO, Roberto Sidinei. Atos de currículo e Autonomia Pedagógica: o 


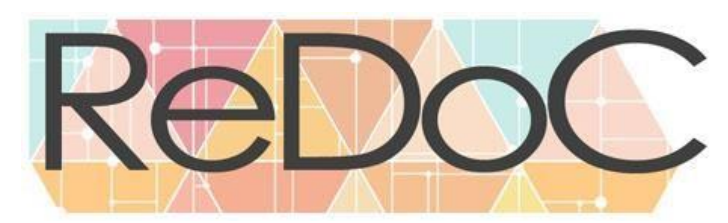

Revista Docência e Cibercultura

socioconstrucionismo curricular em perspectiva. Petropólis, RJ: Vozes, 2013.

MARTINS, Vivian; e ALMEIDA, Joelma. EDUCAÇÃO EM TEMPOS DE PANDEMIA NO BRASIL: SABERESFAZERES ESCOLARES EM EXPOSIÇÃO NAS REDES E A EDUCAÇÃO ON-LINE COMO PERSPECTIVA. Revista Docência e Cibercultura, v. 4, n. 2, mai-ago, 2020, p. 215-224. DOI: https://doi.org/10.12957/redoc.2020.51026

PIRES, Desiree; e CASTRO, Amanda Motta. TODO ESPAÇO É POLÍTICO: ATIVISMO DE MULHERES NAS REDES SOCIAIS. Revista Docência e Cibercultura, v.4, n.2, maio-ago, 2020, p. 143-161.DOI: https://doi.org/10.12957/redoc.2020.49604

ROCHA, Ricael Spirandeli; OLIVEIRA, Gustavo Prado e LIMA, Gyzely Suely. ELEARNING COMO FERRAMENTA DIGITAL HÍBRIDA: UMA METODOLOGIA COLABORATIVA NA FORMAÇÃO TÉCNICA. Revista Docência e Cibercultura, v. 4, n. 2, maio-ago, 2020, p. 85-102. DOI: https://doi.org/10.12957/redoc.2020.49453

SILVA, Rejuany Nora Klein. O PERFIL NECESSÁRIO AO PROFESSOR FRENTE À INFLUÊNCIA DA CIBERCULTURA NO CONTEXTO EDUCACIONAL. Revista Docência e Cibercultura, v.4, n.2, maio-ago, 2020, p. 103-118. DOI:

https://doi.org/10.12957/redoc.2020.47919

SOTERO, Elaine; e COUTINHO, Brenda. MEMES, TECNOLOGIAS E EDUCAÇÃO: 'CONVERSAS' COM PROFESSORAS EM TEMPOS DE PANDEMIA. Revista Docência e Cibercultura, v. 4, n. 2, maio-ago, 2020, p. 67-84. DOI:

https://doi.org/10.12957/redoc.2020.50564

VIEIRA, Sebastiao da Silva; e SABBATINI, Marcelo. CULTURA MAKER NA EDUCAÇÃO ATRAVÉS DO SCRATCH VISANDO O DESENVOLVIMENTO DO PENSAMENTO COMPUTACIONAL DOS ESTUDANTES DO $5^{\circ}$ ANO DE UMA ESCOLA DO CAMPO DA CIDADE DE OLINDA-PE. Revista Docência e Cibercultura, v. 4, n. 2, mai-ago, 2020, p. 43-66. DOI: https://doi.org/10.12957/redoc.2020.50671

Este é um artigo de acesso aberto distribuído sob os termos da Licença Creative Commons Atribuição Não Comercial-Compartilha Igual (CC BY-NC4.0), que permite uso, distribuição e reprodução para fins não comerciais, com a citação dos autores e da fonte original e sob a mesma licença. 